Sonic Scope: New Approaches to Audiovisual Culture

\title{
Emily Collins - World Was \\ on Fire
}

\section{Emily Collins}

Published on: Feb 15, 2021

DOI: $10.21428 / 66 f 840 a 4.72 a 8916 c$

License: Creative Commons Attribution 4.0 International License (CC-BY 4.0). 


\section{World Was on Fire}

Emily Collins, York University, Toronto

Watching obscure and gritty lo-fi video art and music videos on YouTube has been a favourite pastime even before Covid-19 forced nearly all leisure activity to the confines of our homes. Few videos resonate in an equally unsettling and mesmerizing manner as the acclaimed Swiss artist Pipilotti Rist's I'm a Victim of This Song (1995). The compelling and totalizing effect resides in part due to the lyrics of the original song, "Wicked Game" (1989) by Chris Isaak, the vocal manipulation and experimentation offered by Rist, and the diaristic, surrealist visual images that accompany the track. Rist embarks on a karaoke-inspired cover version of the song through non-melodic, frenzied shouting of the lyrics that culminate in the final minute to an incessant highpitched screech. The extreme timbre bestows the work with an intensely expressive, jarring and haunting effect. However, the aggressive rendition is only introduced slightly past the halfway mark when the vocal track splits into two. A softer voice precedes the belligerent tone, which enters as a menacing or mocking echo of the first. These opposing voices generate a distinctly tense dialectic, mirrored within the work's visual counterpart.

The visuals cut back and forth between the handheld recording of a mundane, dimly lit hotel café and a digitally rendered skyscape. The latter reveals a series of rapidly moving white, billowing clouds escalating across the screen in resemblance of a credit-roll conveyer belt with fragments of photographs bursting through the cracks, fading in and out between the shapes. Effectively, any sense of haste or anticipation yields to an overwhelming sentiment of lethargic hypnosis. These staggering photographic stills that roll through the sky appear out of date, like snapshots of a time past, a former utopia. In the café, the camera pans incessantly at varying heights and perspectives, revealing Rist's mediating hand, save for some brief moments of pause on miscellaneous elements within the mise-en-scène: light fixtures; a framed print; people reading and in conversation; a waiter behind the bar. Respite in an attempt to reminisce. We get the sense that these images are from a larger narrative and that they are merely pieces or fragments of a whole. From this we are reminded of the terms and conditions of memories and dreams, which is fortified by the song, that the assemblage is never entirely complete. Indeed, Rist's primary concern is capturing and 
cultivating a mood, an atmosphere, for the audience to absorb themselves and fall victim to.

The inscrutability of the imagery, the decipherable yet illogical sequence and unmotivated organization of material, and the movement of both the camera and the clouds reinforce the sense of precarity and frustration within the lyrics. Through the mediation of images and sound, the slow-motion café scene and the accelerated timelapse of the clouds rolling through the sky, Rist gestures towards our perception of time, notably the way in which time morphs through recollection, and the penetration of dreams and our unconscious within our own subjectivities. A timelessness of the lyrics and the scenes transpires through the conflation of a distant past marked by memories and a yearning for a vehement future.

This work is consistent with the feminist provocation and cultural appropriation that has come to be a defining feature across Rist's oeuvre. Namely, noise, perplexity and fantasy are championed for their potential towards resistance and revival. The effect is deeply immersive, visually and aurally indulgent by means of an unnerving and uncanny disruption. The rupture is soothing and affirmative. Pop culture turns alluring avant-garde while desire morphs into commotion and humour. Haptic and sonic sensorial pleasures interlace with the visuals to formulate a dynamic, complex and fiery remix.

\section{Media Cited}

Rist, Pipilotti. I'm a Victim of This Song. Video (colour, sound). 5:06 min. 1995. 